\title{
El acoso laboral y la obligación de seguridad en el trabajo*
}

\author{
Ruth Gabriela Lanata Fuenzalida**
}

\begin{abstract}
RESUMEN
El objetivo del presente trabajo es analizar la relación existente entre la figura del acoso laboral y la obligación que le asiste al empleador de cuidar eficazmente la vida y salud de los trabajadores, conocida como obligación de seguridad. El tema se inserta en el estudio de una arista de la obligación patronal de protección a los trabajadores, nacida por el solo becho de incorporarlos a la organización empresarial, y pretende determinar la naturaleza jurídica del fenómeno en su faceta de riesgo laboral con el objetivo de su armonización con los conceptos contenidos en la Ley $N^{\circ} 16.744$, específicamente, si los daños que se producen en la víctima de acoso laboral, al fracasar las acciones preventivas, son constitutivos de una enfermedad profesional o de un accidente del trabajo.
\end{abstract}

Acoso laboral - seguridad en el trabajo - enfermedad profesional

\section{Labor barassment and the obligation of safety at work}

\begin{abstract}
The aim of this paper is to analyze the relationship between the figure of workplace harassment and the obligation that the employer has, to effectively care for the life and health of workers. The subject is inserted into the study of the aspect of being part of the business organization, and aims to determine the legal nature of the concept as labor risk in order to harmonize their consequences with the regulations of law number 16.744.
\end{abstract}

Workplace harassment - safety in the workplace - work related diseases

* El presente artículo se ha desarrollado en el marco de la investigación asociada al Proyecto CONICYT FONDECYT de Iniciación $\mathrm{N}^{\circ} 11140836$ "Análisis crítico de la regulación del acoso laboral en Chile y determinación de las vías procesales para su sanción y resarcimiento de los perjuicios causados”. La autora agradece a CONICYT el financiamiento de esta investigación.

** Licenciada en Ciencias Jurídicas y Sociales, Universidad de Concepción. Doctora en Derecho de la Universidad Nacional de Rosario, Argentina. Profesora de Derecho del Trabajo y Seguridad Social, Universidad de Concepción. Correo electrónico: rlanata@udec.cl.

Artículo recibido el 7.10.2016 y aceptado para su publicación en este número el 5.1.2018. 


\section{Planteamiento del problema}

E 1 año 2012 se incorporó a nuestro sistema laboral el concepto de acoso laboral, agregando una norma al artículo 2 del Código del Trabajo, que lo define como toda conducta que constituya agresión u hostigamiento reiterados, ejercida por el empleador o por uno o más trabajadores en contra de otro u otros trabajadores, por cualquier medio y que tenga como resultado para el o los afectados su menoscabo, maltrato o humillación, o bien amenace o perjudique su situación laboral o sus oportunidades en el empleo. El legislador calificó la figura como contraria a la dignidad del trabajador y la consagró como una causal de terminación del contrato de trabajo, pero nada indicó respecto de las demás consecuencias que puede ocasionar, especialmente, en la salud de la víctima.

Si bien no constituye una exigencia legal para la configuración del acoso laboral, es frecuente que, además de la consecuente humillación o perjuicios laborales, ocasione en la víctima diversas afecciones a su salud, tanto físicas como psíquicas. En efecto, por lo general se producirán trastornos de tipo psicológico y psicosomático, aun cuando también suelen ser la causa de otras dolencias, como tensión muscular, trastornos digestivos, lumbalgias, cefaleas, sensación de falta de aliento o de opresión en el pecho ${ }^{1}$.

Por otra parte, el decreto supremo No 109, del Ministerio de Salud, de 1968, califica como enfermedades profesionales a "las neurosis profesionales incapacitantes", indicando a modo de ejemplo algunas formas que estas pueden adoptar, esto es, trastorno de adaptación, trastorno de ansiedad, depresión reactiva, trastorno por somatización y por dolor crónico. Considera como trabajos que pueden provocarlas a todos aquellos que expongan al riesgo de tensión psíquica y se compruebe relación de causa a efecto.

El problema que interesa dilucidar es, entonces, si esas consecuencias en la salud del trabajador constituyen efectivamente una enfermedad profesional. Las dudas se suscitan debido a que, según lo estipula la Ley $\mathrm{N}^{\circ}$ 16.744, es tal la causada de una manera directa por el ejercicio de la profesión u oficio que realiza una persona y que le produzca incapacidad o muerte. La respuesta positiva implica, por tanto, sostener que el acoso laboral constituye un fenómeno ligado íntimamente al ejercicio de toda actividad laboral, de manera tal que sus consecuencias en la salud del trabajador puedan considerarse causadas directamente por su ejercicio o, en otras palabras, que las conductas que lo constituyen puedan llegar a ser la respuesta necesaria del ejercicio del trabajo u oficio del afectado, conclusión que pareciera tener un efecto restrictivo frente al análisis de los alcances de la obligación de seguridad que le asiste al empleador, pues se estaría frente a un elemento del trabajo mismo, a una especie de mal necesario más que a un proceder indebido y abominable de otros trabajadores o del mismo empleador. Tal afirmación conduce a la necesidad de analizar la relación existente entre acoso laboral y riesgo del trabajo. Lo dicho no puede ser entendido como la negación de su carácter intrínsecamente laboral

${ }^{1}$ Hirigoyen M.F. Todo lo que hay que saber sobre el acoso moral en el trabajo. Editorial Paidós, Buenos Aires, traducción de Montserrat Asensio Fernández, 2014, pp. 65 y 66. 
ni, menos aún, como la exclusión de la obligación de prevención del empleador o del cuidado eficaz de la vida y salud de sus trabajadores. En efecto, tal obligación afecta directamente al empleador, sea que se esté en presencia de una enfermedad profesional o de un accidente del trabajo.

\section{Concepto ACtuAl DE FACTORES DE RIESGOS LABORALES}

La preocupación por la seguridad ocupacional de los trabajadores ha sido un tema en constante evolución, de manera tal que el concepto mismo de factores de riesgos laborales no ha permanecido estático en el tiempo. No se puede desconocer que todos los aspectos propios o inherentes a una vida en sociedad conllevan la exposición a determinados riesgos, lo que, evidentemente, alcanza a toda organización laboral. El reconocimiento de esta realidad es el primer escalón en la búsqueda de la protección de los trabajadores dependientes de un empleador, cualquiera sea la organización laboral en la que se desempeñen.

Se ha constatado que la realización del trabajo dependiente no implica solo poner en riesgo la salud física del trabajador, sino también su integridad psíquica y, en la misma idea, los factores de riesgo no se reducen ya a elementos físicos o químicos con los que debe convivir el trabajador en la realización de sus labores, resultando, en la actualidad, familiar la expresión riesgos nuevos o emergentes, los que son el resultado no solo del nacimiento de nuevas formas de trabajo, sino también de los permanentes cambios socioeconómicos, normativos u organizativos, que dan lugar a cambiantes escenarios en las faenas productivas y centros de trabajo y las subsecuentes modificaciones de ciertas condiciones en la forma de asumir esas labores. Estos cambios pueden implicar riesgos para la seguridad y salud para los trabajadores, cuya magnitud y consecuencias son difícilmente valoradas en la actualidad. No se trata ya de circunstancias de fácil apreciación o constatación por los sentidos, sino de diversas repercusiones en la salud de los trabajadores muy difíciles de cuantificar, por un lado, y de justificar científicamente las consecuencias que pueden tener para la salud, por el otro.

No obstante lo señalado, es indudable que la complejidad de la organización de las labores productivas actuales ha significado la aparición o realce de ciertos factores de riesgos laborales a los que se hallan sometidos los trabajadores, los que van más allá de los que tradicionalmente se han conocido como tales. Ello obedece a que esos factores de riesgos no son estáticos, sino que guardan relación con la forma misma de organización empresarial, constituyendo peligros ilimitados y permanentemente en aumento, ya sea por su misma naturaleza o por el creciente número de trabajadores que se exponen a los mismos.

En el marco de estos nuevos factores de riesgo, insertos en las modernas formas de organización de la actividad productiva, conjuntamente con los cambios tecnológicos, sociales y organizativos destacan los denominados psicosociales, noción definida ya hace más de veinte años por la Organización Internacional del Trabajo al indicar que "Los factores psicosociales en el trabajo consisten en interacciones entre el trabajo, su 
medio ambiente, la satisfacción en el trabajo y las condiciones de su organización, por una parte, y por la otra, las capacidades del trabajador, sus necesidades, su cultura y su situación personal fuera del trabajo, todo ello, mediante percepciones y experiencias, pueden influir en la salud y en el rendimiento y la satisfacción en el trabajo"2 ${ }^{2}$. Consideró estos elementos como factores humanos del medio ambiente de trabajo en continua interacción dinámica.

Ya por esos años el organismo internacional había enunciado una enumeración de los factores de riesgos laborales considerando como tales la sobrecarga en el trabajo, la falta de control, el conflicto de autoridad, la desigualdad en el salario, la falta de seguridad en el trabajo, los problemas de las relaciones laborales y el trabajo por turnos. No es difícil observar que las cosas no han cambiado, conservando su actualidad tanto la noción como el listado.

En Chile, el año 2013 se diseñó por el Ministerio de Salud un Protocolo para la Vigilancia de Riesgos Psicosociales en el Trabajo, advirtiendo que estos últimos no pueden ser tratados de manera equivalente a los riesgos físicos, químicos y biológicos, lo que lleva como consecuencia que su evaluación y vigilancia implique la revisión de las condiciones laborales. Entre los factores de riesgos de esta naturaleza consignó la existencia de demandas psicológicas, toda forma de violencia y las relaciones al interior del trabajo ${ }^{3}$. Como se aprecia, no se trata de riesgos emanados de la realización de una labor específica, sino transversal a la misma organización laboral.

Estos riesgos nuevos o emergentes pueden provenir de la innovación técnica, del cambio social u organizativo y de la aplicación de nuevas tecnologías en los procesos de producción, pero también de las actuales condiciones laborales, como ocurre por ejemplo con la sobrecarga de trabajo resultante de la creciente competitividad, con las nuevas formas de organización laboral constituidas por las diversas variantes de la tercerización y con los denominados riesgos ergonómicos. Estos factores no constituyen de por sí elementos de carácter negativo, lo que no significa que no deba ponerse cuidado en sus eventuales consecuencias en la vida y salud de los trabajadores ${ }^{4}$.

Se entiende, por tanto, por riesgo emergente cualquier riesgo nuevo que va en aumento. Nuevo, porque no solo alude a aquellos que no existían, sino también a los emanados de algún factor conocido, pero que solamente en estos momentos se considera riesgo debido a nuevos descubrimientos científicos o percepciones sociales.

El aumento, por su parte, se evidencia en el crecimiento de las situaciones de peligro, estos es, del aumento de las probabilidades de exposición al riesgo o bien de la

\footnotetext{
${ }^{2}$ Organización Internacional del Trabajo, "Factores Psicosociales en el Trabajo: Naturaleza, incidencia y prevención”, en: Serie seguridad, higiene y medicina del trabajo. Ginebra, 2015, núm. 56. Disponible en: http://www.ilo.org/wcmsp5/groups/public/---americas/---ro-lima/documents/publication/wcms_180285. pdf, visitado en 9 de septiembre de 2016.

${ }^{3}$ Ministerio de Salud, Protocolo de Vigilancia de Riesgos Psicosociales en el Trabajo, 2013, p. 12. Disponible en http://web.minsal.cl/portal/url/item/e039772356757886e040010165014a72.pdf

${ }^{4}$ Moreno B. "Factores y riesgos laborales psicosociales: conceptualización, historia y cambios actuales", en Medicina, seguridad y trabajo, vol.57, suppl. 1, 2011, p.7.
} 
seriedad o magnitud creciente de sus efectos en la salud de los trabajadores. En el decir de Rodríguez y San Martín, la denominación emergente alude a que se trata de eventualidades que están aflorando y, si emergen, es porque han estado tapados u ocultos 5 .

Además, no es fácil enumerar los riesgos psicosociales, pues como ha indicado la Agencia Europea para la Seguridad y la Salud en el Trabajo ${ }^{6}$ están íntimamente vinculados al modo en que se desarrolla actualmente el trabajo y el contexto económico y social en el que está llamado a configurarse, lo que de por sí origina un estado de estrés en el trabajador el que puede llegar a dañar seriamente su salud.

\section{LA VIOLENCIA EN EL TRABAJO COMO RIESGO LABORAL}

Los factores ya aludidos pueden desembocar en diversas formas de lesión a los derechos de los trabajadores, pues tienden a generar un ambiente propicio para la configuración de toda clase de manifestación de violencia laboral, entendida por la Organización Internacional del Trabajo como "Toda acción, incidente o comportamiento que se aparta de lo razonable mediante el cual una persona es agredida, amenazada, humillada o lesionada por otra en el ejercicio de su actividad profesional o como consecuencia directa de la misma". La violencia puede ser interna y externa; la primera tiene lugar entre los trabajadores, incluidos directores y supervisores, y la externa entre trabajadores (y directores y supervisores) y toda otra persona presente en el lugar de trabajo ${ }^{7}$.

Sin duda alguna que una de las más abominables materializaciones de la violencia en el ambiente de trabajo es el acoso laboral, figura que, de esta forma, se tipifica como un serio riesgo para la vida y seguridad del trabajador y, como tal, en el esquema de regulación nacional constituye parte de las obligaciones que asume el empleador por mandato del artículo 184 del Código del Trabajo.

Lo señalado lleva fácilmente a concluir que, aun cuando en la consagración legal no se haya indicado de manera expresa, la falta de prevención de las conductas que lo configuran puede y debe ser sancionada, según se analizará.

Debido a la definición de acoso laboral consagrada en nuestra legislación es posible pensar que se está frente a una figura calificada por el resultado, es decir, se materializa por el acaecimiento de conductas constitutivas de agresión u hostigamiento reiterados que produzcan los efectos que la norma indica, sin exigirse la acreditación de alguna intencionalidad en el victimario. Se une a ello la enumeración de factores que pueden ser los que llevan a su configuración, los que considerados de manera aislada e independiente

${ }^{5}$ Rodríguez G. y San Martín C. "La protección por la Seguridad Social de los riesgos psicosociales", en González, F. y Hierro, F. (coord.), Los Riesgos Psicosociales: Teoría y Práctica, Editorial Aranzadi S.A., Navarra, España, 2009, p. 211.

${ }^{6}$ En https://osha.europa.eu/es/tools-and-publications/publications/factsheets/74/view

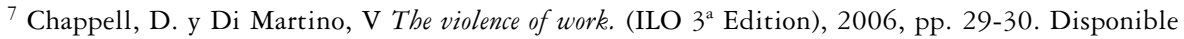
en http://www.ilo.org/wcmsp5/groups/public/---dgreports/---dcomm/---publ/documents/publication/ wcms_publ_9221108406_en.pdf Visitado en 20 de agosto de 2016. 
a menudo se presentan como carentes de toda ilicitud, por lo que exigir evitar que se produzcan puede resultar un ilógico imposible de cumplir.

Las manifestaciones de violencia en la vida en sociedad han ido expandiéndose y asumiendo diversas formas, de manera tal que se han debido adoptar medidas que permitan la protección de los particulares frente a aquellas. La vida en la empresa no está ajena, por tanto, a la existencia de estas atípicas formas de violencia, las que adoptan una especial importancia cuando se insertan en la organización laboral, fenómeno que debe ser considerado por el obligado a la protección de la vida y salud de los trabajadores. Como se dijo, la Organización Internacional del Trabajo considera como uno de los factores del estrés laboral las relaciones laborales.

En Chile se trata de un problema preocupante, sobre todo si se considera que según información de la Asociación Chilena de Seguridad al 2013 las enfermedades profesionales que lideran las estadísticas son las de salud mental, con $40 \%$ del total de enfermedades, y dentro de ellas las neurosis ocupacionales alcanzan al 50\%, agregándose a las patologías conocidas como estrés, otros síntomas como decaimiento y falta de productividad laboral ${ }^{8}$.

\section{LA OBLIGACIÓN DE SEGURIDAD EN LA LEGISLACIÓN CHILENA Y SU RELACIÓN CON EL ACOSO LABORAL}

El Código del Trabajo destina su Libro II a lo que denomina Protección a los Trabajadores, regulación que se divide en dos títulos. El primero de ellos, bajo el epígrafe Normas Generales, contiene disposiciones cuya considerable trascendencia parece escapar al carácter que se le atribuye a ese epígrafe. Se trata, por tanto, de una normativa cuyo carácter general dice relación con su ámbito de aplicación, esto es, se contemplan obligaciones para todo empleador por el solo hecho de constituir parte de una relación laboral. La regla general en la materia está constituida por el artículo 184 del texto legal, el que contempla la obligación de seguridad que pesa sobre al empleador, al exigirle proporcionar al trabajador "condiciones adecuadas de higiene y seguridad en el trabajo". El legislador entiende que la eficiencia se habrá logrado cuando las condiciones son las “adecuadas", calificativo que pareciera determinar la naturaleza misma de las acciones adoptadas, las que pasan a tener relación directa o depender del trabajo específico que cada trabajador realiza9.

La norma, a continuación, establece pautas concernientes a la forma en que se debe dar cumplimiento a la obligación, al agregar que el empleador debe informar de los posibles riesgos y mantener las condiciones adecuadas de higiene y seguridad en las faenas, como también los implementos necesarios para prevenir accidentes y

${ }^{8}$ Según información de la Asociación de Mutualidades. Disponible en http://www.asociaciondemutuales. $\mathrm{cl} / \mathrm{p}=4343$. Visitado en 20 de agosto de 2016.

${ }^{9}$ Sobre esta materia puede verse Lanata Fuenzalida G. Manual de legislación previsional. Thomson Reuters, Santiago, 2014, segunda edición, pp. 371 a 417. 
enfermedades profesionales, expresiones que llevan a un entendimiento racional de la obligación impuesta al empleador, pues es evidente que la eliminación absoluta de todo riesgo es un imposible que, ni siquiera en cumplimiento del principio protector, podría ser razonablemente exigible.

Se trata de una obligación que se materializa en acciones concretas, reconocidas en el Código Sanitario, cuyo artículo 82 entrega a un reglamento el establecimiento de normas relativas a la higiene y seguridad de los lugares de trabajo, referidas en general a cualquier elemento, con el fin de proteger eficazmente la vida, la salud y bienestar de los trabajadores y empleador y de la población en general. En virtud de esta norma el 15 de septiembre de 1999 se dictó el decreto supremo No 594, del Ministerio de Salud, que aprobó el Reglamento para las Condiciones Sanitarias y Ambientales Básicas en los Lugares de Trabajo, cuya normativa, si bien resalta los medios físicos que los lugares de trabajo deben reunir, descansa sobre la base de la obligación amplia y general de las empresas de mantener las condiciones ambientales necesarias para proteger la vida y salud de los trabajadores.

Esta obligación ha sido materia de profusos pronunciamientos por los tribunales de justicia, determinando que el empleador es un deudor de seguridad a sus trabajadores, lo que constituye una manifestación del deber general de protección, cuyo cumplimiento constituye un principio que se encuentra incorporado en todo contrato, siendo un elemento de su esencia, por lo que no queda entregada a la voluntad de las partes sino que comprende ciertas pautas cuyo contenido, forma y extensión se encuentran reguladas mediante las normas de orden público ${ }^{10}$. El artículo 184 del Código del Trabajo pone de cargo del empleador acreditar que ha cumplido con este deber legal de cuidado si el accidente ha ocurrido dentro del ámbito de actividades que están bajo su control, debiendo, en principio, presumirse su culpa por el hecho propio, correspondiendo probar la diligencia o cuidado a quien ha debido emplearlo. En otras palabras, según los sentenciadores, si se verifica un accidente del trabajo se presume que el empleador no tomó todas las medidas necesarias para evitarlo, o que las adoptadas fueron insuficientes o inapropiadas, presunción que surge de la obligación de seguridad impuesta por el legislador ${ }^{11}$.

Sin embargo, aun compartiendo la tesis de la jurisprudencia en orden a que el tenor literal del precepto lleva a concluir que se ha exigido al empleador la esmerada diligencia que un hombre juicioso emplea en la administración de sus negocios importantes, es decir, que responde hasta de la culpa levísima, ello no puede significar que está obligado a obtener la desaparición absoluta del riesgo, cuestión que evidentemente constituiría la imposición de una obligación imposible de cumplir. De ahí que la ley solo haya exigido que se adopten las medidas adecuadas y no que asegure un ambiente de trabajo exento de todo riesgo. En efecto, la Corte Suprema ha sostenido que las medidas necesarias que

${ }^{10}$ Corte Suprema, sentencia dictada el 30 de agosto de 2007, en causa rol 3619-2016.

${ }^{11}$ Corte Suprema, sentencia de 5 de noviembre de 2013, pronunciada en causa rol 9163-2012. Estos planteamientos han sido recogidos, recientemente, en sentencia de en fallo de 12 de septiembre de 2016, dictado en causa rol 37.032-2015. 
debe tomar el empleador, dependerán de la situación concreta de los servicios que presta el trabajador y de los riesgos a que está expuesto con su labor, lo que bien puede significar la adopción de medidas que no constituyen obligaciones legales o administrativas. $\mathrm{Y}$ agrega que no puede entenderse que la referida obligación comprenda la adopción de una medida que la autoridad o la ley se ha limitado a sugerir o recomendar, ya que debe presumirse que esta no reúne las condiciones que la hagan indispensable para la prevención de accidentes o bien presenta dificultades de otra índole que no aconsejan imponerla obligatoriamente, concluyendo que el empleador, en el caso en estudio, no había incumplido la obligación que impone el artículo 184 del Código del Trabajo, pues la medida en cuestión no aparecía como eficaz para el fin que se persigue y presentaba dificultades en su adopción.

Debe tenerse presente que el marco general al respecto lo establece la propia Ley $\mathrm{N}^{\mathrm{o}} 16.744$ al exigir en su artículo 69 la presencia de culpa en el empleador para hacerlo responsable de los daños que puedan haberse ocasionado al trabajador, norma que si bien no establece el grado de exigencia que se le ha impuesto, sí exige su presencia, sin esta no nace la obligación de indemnizar los daños no cubiertos por el sistema de Seguridad Social.

El Código del Trabajo estableció, eso sí, una obligación de carácter contractual amplia, que implica, entre otras cosas, una presunción de culpa respecto del contratante incumplidor, de manera tal que será el empleador quien deberá acreditar que adoptó todas las medidas adecuadas para evitar que se produzca un daño a la salud del trabajador y, no obstante su diligencia, ello igualmente aconteció. Implica, por tanto, la implementación de medidas preventivas, esto es, que le permitan al trabajador el cumplimiento seguro de sus obligaciones contractuales. Así entonces, la organización empresarial debe necesariamente realizar acciones tendientes a determinar los factores de riesgos a los que están expuestos los trabajadores en su empresa, teniendo en consideración que, en la actualidad y atendido el contexto tecnológico vigente, es posible reducir al máximo la aleatoriedad propia de las actividades preventivas, permitiendo alcanzar la eficacia exigida por la ley ${ }^{12}$, apreciación que encuentra su respaldo en la calidad de derecho fundamental que reviste el derecho de los trabajadores a la seguridad y salud en el trabajo ${ }^{13}$.

Se exige, en este cometido, buena fe por parte del empleador, buena fe que asiste a todo contratante, pero que en este particular caso se materializará solamente si ha desplegado todos los medios a su alcance para evitar la producción del infortunio ${ }^{14}$, realidad que no escapa a las conductas de acoso laboral, en las que la prevención es decisiva a la

${ }^{12}$ Núñez González, C. Prevención de riesgos laborales en Chile. Alcance y contenido del artículo 184 del Código del Trabajo. Librotecnia, Santiago, 2014, segunda edición actualizada, p. 91.

${ }^{13}$ Acerca de este tema puede verse Lanata Fuenzalida G. "El derecho de los trabajadores a la seguridad y salud en el trabajo como derecho fundamental”, en Caamaño, E. Y. Pereira R. (coord.), Estudios de Derecho del Trabajo y de la Seguridad Social. Doctrina chilena y extranjera, Editorial AbeledoPerrot, Santiago, 2012, pp. 137-184.

${ }^{14}$ Lanata Fuenzalida G. Manual de legislación previsional. Thomson Reuters, Santiago, 2014, segunda edición, pp. 378 y 379. 
hora de evitar daños al trabajador, exigiéndose un mayor grado de diligencia, pues debe propenderse a la desaparición absoluta de las conductas constitutivas de acoso.

\section{El ACOSO LABORAL, CONSIDERADO COMO RIESGO LABORAL}

Según la definición contenida en el artículo 2 del Código del Trabajo el acoso laboral, para poder calificarse de tal, debe tener como resultado el menoscabo, maltrato o humillación para el, o los afectados o bien constituir amenaza o perjuicio en su situación laboral o sus oportunidades en el empleo. La ley no exige una consecuencia ni específica ni genérica en la vida o salud de la persona, aun cuando la expresión maltrato incluye la posibilidad de causar alguna dolencia o enfermedad.

Para un adecuado entendimiento del problema, debe diferenciarse el acoso laboral del estrés laboral, fenómeno este último que ha sido visto como un riesgo en sí mismo, pero que en realidad constituye, más bien, el resultado o consecuencia de ciertas circunstancias específicas. Representa la carga psíquica que puede implicar el desarrollo del trabajo la que, a su vez, puede tener su causa en diversos factores. El denominado estrés laboral o estrés relacionado con el trabajo, se manifiesta cuando el trabajador siente que su entorno de trabajo le exige más de lo que él puede asumir (o controlar) y puede ser la causa de diversas alteraciones en su salud, las que pueden tener un carácter tanto físico como psíquico o emocional. Entre estos factores de riesgo se incluyen no solo aquellos que emanan de la realización misma del trabajo, como ruidos y temperaturas extremas, sino también los que son consecuencia de la organización laboral, así como ascensos vinculados al cumplimiento de metas, la falta de posibilidades adecuadas para una conciliación del trabajo con la vida familiar o la competitividad excesiva. Lo cierto es que cualquiera que sea la causa que lo motiva, el estrés laboral ocupa un nivel importante en las alteraciones a la salud de los trabajadores ${ }^{15}$. Por otra parte, según la Organización Internacional del Trabajo, el estrés es la respuesta física y emocional a un daño causado por un desequilibrio entre las exigencias percibidas y los recursos y capacidades percibidos de un individuo para hacer frente a esas exigencias ${ }^{16}$. Está determinado por la organización del trabajo, el diseño del trabajo y las relaciones laborales. $\mathrm{Y}$ es precisamente en este último aspecto en donde podemos encasillar al acoso laboral. Se confirma, por tanto, que estrés y acoso laboral no son sinónimos, sino que

${ }^{15}$ En la Unión Europea se estima que entre el $50 \%$ y el $60 \%$ de los días laborales perdidos se vinculan al estrés laboral. Agencia Europea para la Seguridad y Salud en el Trabajo Riesgos Nuevos y Emergentes para la Salud y Seguridad en el Trabajo. Observatorio Europeo de Riesgos, 2009, p. 21. Disponible en http://www. cigsaudelaboral.org/files/descargas/RIESGOS\%20NUEVOS\%20Y\%20EMERGENTES.\%20Observatorio\%20 Europeo\%20de\%20Riesgos.pdf. Visitado en 28 de agosto de 2016.

${ }^{16}$ Organización Internacional del Trabajo. Estrés en el trabajo: Un reto colectivo. Servicio de Administración del Trabajo, Inspección del Trabajo y Seguridad y Salud en el Trabajo, LABADMIN/OSH. Ginebra: OIT, 2016, p. 2. Disponible en http://www.ilo.org/public/libdoc/ilo/2016/490658.pdf. Visitado en 28 de agosto de 2016. 
este último puede ser la causa del anterior. En otras palabras, una de las consecuencias de las conductas constitutivas de acoso laboral, pero no la única.

El tratamiento del tema no ha sido sencillo, por un lado, porque generalmente se considera que las patologías derivadas de las conductas de acoso laboral están constituidas por enfermedades psíquicas y, por el otro, porque estas pueden presentar un origen común y no solamente profesional ${ }^{17}$.

\section{ACOSO LABORAL y ENFERMEDAd PROFESIONAL}

El acoso laboral no es en sí una enfermedad profesional, no obstante la peligrosa cercanía existente entre ambos fenómenos. El tema merece un análisis cuidadoso. Desde ya, es pertinente considerar que debe enfocarse como la causa de una afectación psíquica o física, pero no como la afectación en sí misma. El punto a dilucidar, entonces, es si esas afectaciones pueden o no ser calificadas como enfermedad profesional, según la conceptualización contenida en la legislación chilena.

La enfermedad profesional está definida en el artículo 7 de la Ley $\mathrm{N}^{\circ} 16.744$ como aquella que se produce por el ejercicio directo de la profesión u oficio que realiza una persona y que le produce incapacidad o muerte.

La declaración de la calidad de profesional de una enfermedad puede ser efectuada por dos vías: la primera de ellas, por medio de su incorporación en la enumeración contenida en un reglamento, exigiendo la ley su revisión cada tres años y, la segunda, como el resultado de su acreditación por el afectado ante el organismo administrador, en aquellos casos en que la enfermedad no se encuentre en la enumeración contenida en el reglamento aludido. Es así como el decreto supremo $\mathrm{N}^{\circ} 109$, del Ministerio de Salud, de 1968, califica como enfermedades profesionales a "las neurosis profesionales incapacitantes", indicando a modo de ejemplo algunas formas que estas pueden adoptar, esto es, trastorno de adaptación, trastorno de ansiedad, depresión reactiva y trastornos por somatización y por dolor crónico. Considera como trabajos que pueden provocarlas a todos aquellos que expongan al riesgo de tensión psíquica y se compruebe relación de causa a efecto. La norma, en su texto original, se limitaba a calificar como enfermedad

${ }^{17}$ En un estudio publicado en 2011, destinado a comparar las realidades de personas que consultaban por trastornos emocionales que eran calificados como enfermedad común o como neurosis profesionales, se constató que los primeros eran significativamente más sintomáticos y que los síntomas que mejor los diferenciaban eran que en las enfermedades comunes predominaban los de tipo depresivo, siendo los principales motivos de consulta en estos casos los "conflictos interpersonales y sentimientos de subvaloración", mientras que en aquellos de origen profesional estaban constituidos por la "presión de trabajo" y "sobrecarga”. Sin embargo, en los primeros (enfermedades comunes) los conflictos se situaban en "ambiente laboral poco agradable". Concluyeron los especialistas que la obligación de calificar las patologías como comunes o profesionales es un tema de gran complejidad, debido a las similares características que aquellas presentan. Denunciaron, asimismo, el aumento sostenido de consultas por trastornos mentales atribuidos al trabajo detectándose una estrecha relación entre factores psicosociales inidentificables en el trabajo. Trucco B., M. y Rebolledo M. Policarpo. "Neurosis profesional o enfermedad común: Síntomas y estresores", en Revista Médica de Chile, $\mathrm{N}^{\circ} 139,2011$, p. 1376. 
profesional a las neurosis profesionales. Solo el 2005, mediante la dictación de un nuevo decreto $^{18}$, se resolvió agregar algunas de las formas que estas neurosis pueden adoptar. La Superintendencia de Seguridad Social informó que el propósito de esas menciones obedecía a que el listado vigente hasta entonces no había sufrido modificaciones en lo que se refería a las enfermedades psiquiátricas desde la fecha de su publicación en 1968, en circunstancias que se habían producido cambios en sus terminologías ${ }^{19}$. Se continuó exigiendo la relación de causa a efecto. Es posible señalar que la jurisprudencia del organismo administrativo ya con anterioridad a las modificaciones se había pronunciado en este mismo sentido, dictaminando, por ejemplo, ya en 1993, que las características circunstanciales del trabajo desempeñado por una trabajadora, esto es, como profesora con una carga excesiva de trabajo por haber tenido a su cargo dos numerosos cursos eran los que habían desencadenado la neurosis que padecía, por lo que esta presentaba un carácter profesional $^{20}$. De similar forma concluyó al conocer del caso de una trabajadora que se desempeñaba en un hospital y cuya neurosis incapacitante había sido provocada por los ruidos molestos existentes en el lugar de trabajo ${ }^{21}$. Los casos reseñados no merecen dudas en cuanto a su carácter profesional, pues se trata del desempeño en trabajos a los que les son inherentes los riesgos que les provocaron las neurosis. El 2005, haciéndose cargo de la importancia de las afecciones psíquicas en los trabajadores, emitió un informe ${ }^{22}$, sosteniendo que es y debe ser considerada enfermedad profesional cualquier patología que se hubiera contraído a causa o con ocasión del trabajo, a pesar de no estar incluida en la enumeración contenida en el reglamento, la que no tiene un carácter taxativo, lo que ha permitido superar las dificultades que se han denunciado al estudiar la situación análoga en la legislación española, en que se ha sostenido que ha sido la imposibilidad de encuadrar determinadas patologías psíquicas contraídas con ocasión del trabajo en el concepto de enfermedad profesional, por no encontrarse contenida en la lista cerrada de enfermedades dispuesta por la ley. Pero en Chile no parece ser esa la causa del problema. En efecto, en el sistema chileno es factible que el afectado por la enfermedad pueda solicitar la declaración de su origen profesional ${ }^{23}$, siempre que se acredite la relación de causalidad directa que exige la ley.

${ }^{18}$ Decreto $\mathrm{N}^{\circ} 73$, publicado en el Diario Oficial de 7 de marzo de 2006.

19 Dictamen 03376, de 27 de enero de 2005, disponible en http://sistema.suseso.cl/Produccion/ jurisprudencia252.nsf/Jurisprudencia_F.xsp?action=openDocument\&documentId=2B06A.

${ }^{20}$ Dictamen 9716, de 1 de octubre de 1993, disponible en http://sistema.suseso.cl/Produccion/ jurisprudencia252.nsf/Jurisprudencia_F.xsp?action=openDocument\&documentId=7166

21 Dictamen 3037, de 15 de octubre de 1979, disponible en http://sistema.suseso.cl/Produccion/ jurisprudencia252.nsf/Jurisprudencia_F.xsp?action=openDocument\&documentId =FAE

${ }^{22}$ Dirigido a la diputada Ximena Vidal Lázaro, que pretendía proponer una iniciativa legislativa para incorporar la depresión como una enfermedad profesional. Dictamen 03376, de 27 de enero de 2005, disponible en http://sistema.suseso.cl/Produccion/jurisprudencia252.nsf/Jurisprudencia_F.xsp?action=ope nDocument\&documentId=2B06A

${ }^{23} \mathrm{El}$ inciso final del artículo 7 de la Ley $\mathrm{N}^{\circ} 16.744$ permite a los afiliados acreditar ante el respectivo organismo administrador el carácter profesional de alguna enfermedad que no estuviere enumerada en la lista aludida y que hubiesen contraído como consecuencia directa de la profesión o del trabajo realizado. 
El acoso laboral, como se ha venido diciendo, constituye un riesgo propio de los lugares de trabajo y puede llegar a ocasionar incapacidad, pero no parece ser producido por el ejercicio directo de la profesión u oficio que realiza la persona. La relación de causa a efecto entre el trabajo y la afectación a la salud es indiscutible, pero es posible preguntar si efectivamente se trata de una enfermedad profesional siguiendo las pautas consagradas en el artículo 7 de la Ley $\mathrm{N}^{\circ}$ 16.744.

Cierto es que las conductas constitutivas de acoso laboral pueden llegar a producir efectos serios en la salud del trabajador, pero estos solo pueden calificarse como el resultado de una enfermedad profesional en la medida que se acepte que aquellas constituyen un riesgo implícito en cualquier actividad laboral o que es el ejercicio de una profesión $\mathrm{u}$ oficio el que expone al riesgo, siguiendo el esquema legislativo chileno. El decreto supremo $\mathrm{N}^{\circ} 109$, ya aludido, por lo general, considera ciertos agentes presentes en determinada actividad como causantes de una enfermedad también específica, lo que se condice plenamente con el concepto legal contenido en el artículo 7 de la Ley $\mathrm{N}^{\circ} 16.744$. La pregunta a responder entonces es: ¿será posible entender que una afectación a la salud de un trabajador provocada por acoso laboral constituya una enfermedad profesional? La respuesta positiva implica aceptar que el acoso laboral es consecuencia directa de la profesión u oficio que realiza el afectado y no una conducta, a lo menos, indebida de uno o más trabajadores o del empleador.

La autora española Sofía Olarte Encabo, haciéndose cargo de este problema, indica que las lesiones provocadas por el acoso laboral no pueden ser consideradas una enfermedad profesional, por no coincidir con la tipificación legislativa española. La ley española considera como tal "La contraída a consecuencia del trabajo ejecutado por cuenta ajena, en las actividades que se especifiquen en el cuadro que se apruebe por las disposiciones de aplicación y desarrollo de esta ley y que esté provocada por la acción de los elementos o sustancias que en dicho cuadro se indiquen para cada enfermedad profesional" 24 . Descartando luego que se trate de un accidente del trabajo (no coincide con su definición legal), llega a la conclusión de que se está frente a lo que podría denominarse enfermedad del trabajo, la que estaría constituida por alteraciones a la salud que, a diferencia de las enfermedades profesionales en las que hay una relación causaefecto, pueden o no tener una etiología relacionada con el trabajo, es decir, tienen un carácter ambivalente: se trata, concluye, de enfermedades comunes, pero que en algunos casos se originan precisamente como consecuencia del trabajo. Concretamente, sostiene la autora, "una depresión, un síndrome ansioso depresivo... son enfermedades que no tienen por qué tener su causa en el trabajo, pero si se prueba que esta enfermedad aparece como consecuencia de que la persona ha sido sometida a acoso, por ejemplo, dicha enfermedad común pasaría a ser considerada enfermedad del trabajo" ${ }^{25}$. Como se aprecia,

${ }^{24}$ Art. 116 de la Ley General de Seguridad Social.

${ }^{25}$ Olarte, S. "La incidencia del acoso moral en el ámbito del sistema de Seguridad Social: hacia la equiparación de las enfermedades psicolaborales”, en Correa, M. Acoso Moral en el Trabajo. Concepto, prevención, tutela procesal y reparación de daños, Editorial Aranzadi S.A., Navarra, España, 2006, p. 164. 
se está agregando una tercera categoría de riesgo laboral, a pesar de que la ley española solo exige que la lesión se produzca a consecuencia del trabajo, concepto que parece ser más amplio que el contenido en la ley chilena, aun cuando presenta la limitante de la inclusión en un listado de carácter cerrado.

En Chile, la relación con el trabajo de las patologías mentales no ha sido desconocida. El 2001 la Superintendencia de Seguridad Social dictaminó el origen profesional de la "neurosis profesional depresión mayor" que padecía una trabajadora, por existir relación causal directa entre el trabajo realizado y las enfermedades padecidas, decisión que fundamentó en que el cuadro de la paciente reconocía su origen en las condiciones estresantes a que estaba sometida por la existencia de un cambio de puesto de trabajo, que significaba desmedro de su jerarquía. Al no haberse demostrado otra causa que explique el fenómeno concluyó que su origen era profesional ${ }^{26}$. Como se aprecia, se prescindió de la naturaleza específica del trabajo que realizaba la persona, considerando solamente la existencia de causa a efecto entre las dolencias y las condiciones de trabajo. El organismo administrativo adoptó un criterio de calificación amplio, no limitando de manera específica la naturaleza de los factores que pueden provocar las neurosis ni tampoco los trabajos en que pueden originarse, haciendo aplicación de los parámetros que la ley exige para calificar determinada situación como accidente del trabajo, mas no como enfermedad profesional, esto es, que la incapacidad se haya producido por causa u ocasión del trabajo. Sin duda que el acoso laboral es un fenómeno ligado necesariamente a la actividad dependiente de un trabajador, por lo que las incapacidades que se provoquen como resultado de las conductas que lo configuran siempre lo serán con ocasión del trabajo. El problema radica en determinar si resulta jurídicamente factible extender el concepto de enfermedad profesional a situaciones diferentes a aquellas que son causadas de una manera directa por la profesión u oficio que realiza una persona, máxime si el Reglamento $\mathrm{N}^{\circ} 109$ determina que los trabajos susceptibles de producirlas son aquellos que entrañan el riesgo. Por otra parte, la Superintendencia parece extrapolar las nociones de causa u ocasión también a las enfermedades profesionales y no limitar su aplicación a los accidentes del trabajo, decisión que implica alejarse del texto legal, lo que lleva a pensar que no se trata de una solución óptima. Pero ello no significa, en caso alguno, afirmar que las consecuencias del acoso laboral no constituyan lesiones de carácter profesional. Por el contrario, la relación con las actividades laborales queda en evidencia de la sola lectura de la definición contemplada en el artículo 2 del Código del Trabajo. La cuestión a determinar es la calidad de riesgo social de origen profesional que representa descartando, por tanto, toda posibilidad de calificar las patologías provocadas por el fenómeno como de origen común.

En otras palabras, no es factible determinar la existencia de esta figura al margen de la organización laboral, lo que implica un riesgo del trabajo según las pautas dadas por la

${ }^{26} 2713625$ de julio de 2001, disponible en http://sistema.suseso.cl/Produccion/jurisprudencia252. nsf/Jurisprudencia_F.xsp?action=openDocument\&documentId $=839 \mathrm{~A}$ 
Organización Internacional del Trabajo. Pero considerarla como el resultado directo de la profesión u oficio que realiza una persona implica aceptar como íntimamente ligada a toda ocupación u oficio la posibilidad de configurarse el acoso laboral generando, de algún modo, la idea de que el fenómeno es consustancial a toda actividad laboral, al ser el resultado casi necesario, aun cuando prevenible, del ejercicio de la profesión u oficio que realiza la persona.

No obstante lo habitual o generalizado de las conductas de acoso, se trata de una anomalía reprochable y que no constituye un elemento esencial de toda ocupación u oficio, sino una alteración irregular de las condiciones de trabajo. No por ello deja de ser un riesgo laboral, pero constituye más bien una cuestión accidental, cuya configuración o materialización siempre originará algún grado de responsabilidad en el empleador y cuyos efectos nocivos para la salud del trabajador constituyen lesiones sufridas por una persona por causa u ocasión del trabajo, y que le producen incapacidad o muerte, es decir, corresponde a la definición legal de accidente del trabajo contenida en el artículo 5 de la Ley $\mathrm{N}^{\mathrm{o}} 16.744$ y, como tal, cobran aplicación todas y cada una de las normas contenidas en esa normativa protectora, imponiendo diferentes obligaciones al empleador, entre las que figuran las de prevención, cuya omisión implica la infracción a la obligación de seguridad contemplada en el artículo 184 del Código del Trabajo, de manera que la falta de adopción de medidas preventivas configurará responsabilidad en el contratante incumplidor, en este caso, el empleador, con la consecuente obligación indemnizatoria.

\section{Prevención de acoso laboral Considerado Como CUMPlimiento DE LA OBLIGACIÓN DE SEGURIDAD}

Las consecuencias para la salud de los trabajadores, esto es, el daño que provocan o pueden llegar a provocar las conductas constitutivas de acoso laboral presentan una gravedad creciente, por lo que urge acentuar y especificar las medidas de prevención en la empresa, procurando anticiparse a su aparición. No se trata, por tanto, solo de actuar cuando el daño ya está hecho intentando reparar sus consecuencias, sino de evitar que el fenómeno mismo se llegue a configurar, objetivo de mayor factibilidad si se considera que no se trata de las consecuencias directas de la labor del trabajador, sino de la introducción de elementos o factores anómalos, que alteran la regular realización de la labor dependiente.

Por cierto que la eliminación absoluta de los riesgos es un imposible, lo que no quiere significar que quien proporciona trabajo pueda eximirse de asumir las conductas preventivas que corresponda, sin que sea posible pensar que la sola indemnización de los daños al afectado pueda significar el cumplimiento de esas obligaciones. En este entender, Carlos Palomeque ha advertido la instalación en la empresa del denominado riesgo profesional, ya sea ello por la propia naturaleza de la actividad productiva, por las condiciones del lugar donde se realiza el trabajo o como consecuencia de la presencia de una gama plural de elementos externos a la prestación laboral que, sin embargo, 
condicionan su desarrollo, concluye el autor: “Trabajo y riesgo profesional están así fatídicamente condenados a cohabitar en el desarrollo de la relación laboral" 27.

Una autora española adhiere a esta tesis al especificar que el deber empresarial de prevenir los riesgos laborales con el fin de garantizar el correlativo derecho subjetivo de los trabajadores no supone un deber de eliminar todos los riesgos derivados del trabajo $y$, en consecuencia, de proporcionarles una seguridad absoluta, ya que ese objetivo en ningún caso resulta posible ${ }^{28}$, lo que no excluye la obligación de asumir un rol activo en las labores preventivas.

Así entonces, la sola idea de asumir que el desempeño de una labor en el marco de un trabajo dependiente implica exposición a riesgos a quien lo realiza, conlleva como necesaria consecuencia el nacimiento de una obligación de prevención para quien se beneficia del trabajo de otro, lo que, a su vez, debe traducirse en el desarrollo de acciones positivas y concretas que permitan, siquiera, la posibilidad de su realización en un marco de seguridad adecuado. Es en este punto en donde mayor trascendencia presenta la negación de constituir el acoso laboral el resultado del ejercicio directo de una profesión u oficio, en cuyo caso la eliminación del factor de riesgo podría constituir un objetivo imposible de cumplir. Por el contrario, se está frente a circunstancias anómalas que se pueden presentar en cualquier organización empresarial, pero a cuyo respecto es factible procurar que desaparezcan de un ambiente laboral concreto.

Del punto de vista psiquiátrico, los programas de prevención de riesgos de alteraciones mentales, en general, diferencian tres etapas en su prevención: primaria, secundaria y terciaria ${ }^{29}$. La prevención primaria implica eliminar el riesgo en sí que puede llegar a provocar la alteración de la salud en la persona; la prevención secundaria persigue reducir el impacto del daño y la terciaria reducir los daños producidos ${ }^{30}$.

Tratándose de acoso laboral es menester procurar el desarrollo de una prevención primaria. En el sistema chileno, el artículo 184 del Código del Trabajo, que obliga al empleador a cuidar eficazmente la vida y salud de sus trabajadores, no diferencia según cual sea el origen o causa específica de las afectaciones a la salud, comprendiéndose, por tanto, todo daño que pueda sufrir el trabajador en su salud ya sea física o mental. El carácter amplio de la norma implica la obligación para el empleador de realizar toda

${ }^{27}$ Palomeque, C., Conferencia Inaugural del “Encuentro Iberoamericano Riesgo y Trabajo”, Universidad de Salamanca, Fundación MPFRE, pronunciada el 11 de noviembre de 1991, en Actualidad Laboral, núm. 4 , semana 27 enero-2 febrero, 1992, p. 38.

${ }^{28}$ Martín, M. L. El Derecho de los Trabajadores a la Seguridady Salud en el Trabajo, CES Consejo Económico Social, 2006, p. 192.

29 Caplan caracterizó estas etapas preventivas. La prevención primaria, indicó, busca contrarrestar las circunstancias perniciosas antes que tenga ocasión de producir enfermedad; en la prevención secundaria se pretende disminuir la incidencia del riesgo en el grupo social, a través de la disminución de casos y la terciaria (p. 105) busca disminuir sus consecuencias dañosas. Caplan G. Principios de Psiquiatría preventiva. Editorial Paidós, Buenos Aires, 1966, p. 105.

${ }^{30}$ Fernández J. "Perspectivas psicosociales en torno al acoso y violencia psicológica en el trabajo”, en Correa, M. (coord.), Acoso Moral en el Trabajo. Concepto, prevención, tutela procesal y reparación de daños. Editorial Thomzon Aranzadi, 2006, pp. 23-24. 
acción adecuada para el logro de tal fin, por lo que puede afirmarse, sin lugar a dudas, que el Código del Trabajo le ha impuesto la obligación contractual de prevención en todas sus facetas.

Aplicando al acoso laboral la especificación indicada se concluye que la prevención primaria radica en la eliminación de las causas mismas capaces de llegar a configurar el fenómeno, es decir, cualquier conducta que constituya agresión u hostigamiento que tenga como resultado para el o los afectados su menoscabo, maltrato o humillación, o bien que amenace o perjudique su situación laboral o sus oportunidades en el empleo. Como se aprecia, la conceptualización consagrada por nuestra legislación es amplísima, por lo que las conductas pueden ser de cualquier naturaleza, lo que si bien implica un mayor grado de protección puede hacer más difícil su detección. En consecuencia, la primera medida a adoptar es lograr el adecuado conocimiento del mismo por parte de los trabajadores.

Debe reconocerse que nuestra reglamentación no efectúa alusión explícita ni específica a riesgos de esta naturaleza, pero tampoco los excluye. Es conveniente tener en consideración la reciente publicación del decreto $\mathrm{N}^{\circ} 47$, de 4 de agosto de 2016, sobre Política Nacional de Seguridad y Salud en el Trabajo ${ }^{31}$ cuya dictación constituye, en parte, la respuesta de nuestro país a los compromisos asumidos al ratificar el Convenio No 187, de la Organización Internacional del Trabajo, sobre el Marco Promocional para la Seguridad y Salud en el Trabajo ${ }^{32}$. Entre los diez principios que fija como propios de esa política reconoce el respeto a la vida e integridad física y psíquica de trabajadores y trabajadoras como derecho fundamental, sin imponer limitaciones, agregando el compromiso de enfrentar los riesgos laborales con un enfoque preventivo por sobre su protección, el que debe considerarse desde el diseño de los sistemas productivos y puestos de trabajo, priorizando la eliminación o el control de los riesgos en el origen o fuente.

La gestión misma de los riesgos, como política social, se plantea como una responsabilidad del empleador, quien debe dar cumplimiento efectivo a su deber de protección, aun cuando ello es sin perjuicio de la colaboración de los trabajadores en la implementación de las medidas preventivas de conformidad a la normativa vigente. Y la primera forma de prevenir las conductas es la información adecuada, la que está contemplada como una obligación contractual para el empleador tanto en el artículo 184 del Código del Trabajo, ya aludido, como en su reglamentación, la que le impone la obligación de informar oportuna y convenientemente a todos sus trabajadores acerca de los riesgos que entrañan sus labores, de las medidas preventivas y de los métodos de trabajo correctos. Los riesgos son los inherentes a la actividad de cada empresa ${ }^{33}$.

${ }^{31}$ Publicado en el Diario Oficial de 16 de septiembre de 2016.

32 El Convenio fue promulgado por medio de la dictación del decreto $\mathrm{N}^{\circ} 72,19$ de agosto de 2011.

33 Artículo del 21 decreto supremo $\mathrm{N}^{\circ} 40$ de 1969. Si bien la norma detalla luego algunas medidas específicas que debe adoptar, lo hace solo de manera enunciativa y dada su antigua data es comprensible que solo aluda a los riesgos tradicionales. En efecto, obliga a informar, especialmente, acerca de los elementos, productos y sustancias que deban utilizar en los procesos de producción o en su trabajo, acerca de la identificación de los mismos (fórmula, sinónimos, aspecto y olor), respecto de los límites de exposición 
Es evidente que las actividades preventivas pueden no ser iguales para todo empleador, debiendo, como primera acción positiva al respecto, determinar qué lugares de trabajo o grupos de trabajadores están expuestos en mayor medida a factores de riesgos psicosociales, entre los que se encuentra el riesgo de acoso.

Si bien las medidas específicas en la materia dependerán de la naturaleza de la función a realizar, existen medidas que podrían calificarse de genéricas, convenientes de aplicar en cualquier organización empresarial. El empresario, por tanto, tiene la obligación de prevenir la aparición misma de esas conductas, asumiendo acciones tendientes a la información y la formación ${ }^{34}$, las que deben comenzar con la manifestación concreta y expresa del empleador en orden a fijar una posición de reproche frente a aquellas. Pero ello por cierto no es suficiente, pues debe asumir un rol activo en la detección de posibles factores que puedan propiciar la aparición del fenómeno, así como la retribución bajo parámetros de excesiva competitividad en los procesos productivos, horarios extenuantes o la organización interna basada exclusivamente en relaciones jerárquicas, prescindiendo de todo espíritu colaborativo.

Sin duda, la propia víctima es la primera que debiera percatarse de su calidad de tal y la primera medida a adoptar debiera ser la de una reacción temprana y oportuna. Lamentablemente, en los casos que conocemos o que podemos considerar habituales, la víctima no reacciona sino cuando ya la única alternativa que vislumbra como posible es el alejamiento de la organización empresarial; dicho de otra forma, cuando ya el acoso ha funcionado como tal.

He aquí donde la actividad preventiva resultante del ejercicio de la obligación de informar que la ley ha establecido de cargo del empleador puede resultar de una ayuda innegable: la víctima debe ser capaz de saber identificar los primeros signos de acoso, registrarlos e, incluso, reunir las pruebas que le puedan permitir llegar a acreditar su configuración $^{35}$. Este último punto suele ser el mayor escollo para contar con la cooperación de la víctima. Por un lado, se trata de conductas que consideradas una a una pueden aparecer como de poca importancia y, por el otro, pueden no existir antecedentes físicos que las acrediten o no ser de fácil acceso para la víctima, lo que la puede llevar a soportar el avance de este verdadero flagelo hasta que ya la única opción que le parezca viable sea la renuncia al trabajo. Esta realidad confirma la imperiosa necesidad de contar con redes de información adecuadas para los trabajadores, que les permitan no solo vislumbrar oportunamente lo que le está ocurriendo, sino también no pasar por alto todo posible

\footnotetext{
permisibles de esos productos, acerca de los peligros para la salud y de las medidas de control y de prevención que deben adoptar para evitar estos riesgos.

${ }^{34}$ Siguiendo la nomenclatura de Cavas F., "Breves consideraciones sobre la prevención de los riesgos psicosociales”, en González, F. y Hierro, F. (coord.), Los Riesgos Psicosociales: Teoría y Práctica, Editorial Aranzadi S.A., Navarra, España, 2009, p. 115.

35 Marie-France Hirigoyen indica que la dificultad para defenderse de los actos de acoso radica, precisamente en la falta de pruebas adecuadas. Hirigoyen, M. El acoso moral. El maltrato psicológico en la vida cotidiana, Editorial Paidós, Buenos Aires, 2014, p. 153.
} 
antecedente probatorio que le pueda proporcionar cierta seguridad que le ampare en la denuncia de los hechos ${ }^{36}$.

Una de las formas prácticas en que se puede cumplir con esta obligación está constituida por la declaración explícita en el reglamento interno de orden, higiene y seguridad de conductas que, a modo ejemplar, puedan derivar en una forma de acoso laboral, mención que encuentra su respaldo legal en el artículo 154 del Código del Trabajo, que en su numeral 9 contempla como estipulación especial del reglamento las normas e instrucciones de prevención, higiene y seguridad que se deben observar en la empresa o establecimiento ${ }^{37}$.

El artículo 156 del mismo Código alude al reglamento a que se refiere la Ley $\mathrm{N}^{\mathrm{0}}$ 16.744, sobre Accidentes del Trabajo y Enfermedades Profesionales, norma que en su artículo 67 establece la obligación de toda empresa o entidad, cualquiera que sea el número de los trabajadores, de confeccionar, mantener al día y entregar gratuitamente a sus trabajadores un "Reglamento Interno de Higiene y Seguridad en el trabajo", cuyo cumplimiento es obligatorio para los trabajadores ${ }^{38}$.

Se trata, por tanto, de dos reglamentos distintos, no obstante la íntima correlación que existe entre ambos. El reglamento a que hace referencia la Ley $\mathrm{N}^{\circ} 16.744$ es de aplicación más amplia que el regulado en la ley laboral, pues debe existir en toda entidad donde se desarrolle una relación laboral, sin importar el número de trabajadores de la misma, es decir, aun cuando no haya nacido la obligación que impone el artículo 153. Se trata de un conjunto de normas e instrucciones de prevención, higiene y seguridad que emanan de la entidad empleadora y que tienen por objeto regular la ejecución segura del trabajo específico de que se trate. Su cumplimiento es obligatorio para los trabajadores, debiendo controlarse el mismo por parte del empleador. Bajo ningún respecto puede permitirse el desarrollo del trabajo con infracción a sus disposiciones y de insistir en ello el trabajador puede ser despedido, por incurrir en la causal específica del artículo 160 $\mathrm{N}^{\circ} 5$ del Código del Trabajo, pudiendo también constituir un incumplimiento grave de las obligaciones que le impone el contrato.

El decreto supremo $\mathrm{N}^{\circ} 40$, que aprobó el reglamento sobre prevención de riesgos, no hace alusión expresa o directa a las conductas constitutivas de acoso laboral, pero al constituir un riesgo profesional inherente a toda organización productiva, sin duda constituye un mecanismo ideal para proporcionar herramientas de protección que les permitan detectar de manera oportuna la adopción de conductas que pudieran ser constitutivas del fenómeno a todo trabajador, incluidos aquellos que desempeñan el

${ }^{36}$ Babugia M.D. La prueba en el acoso laboral, Editorial BdeF, Enlace Industria Gráfica, S.L., Algete, Madrid, España, 2015, p. 127.

${ }^{37}$ La Dirección del Trabajo ha confirmado tal posibilidad al pronunciarse respecto de los denominados códigos de conducta, de ética o de buenas prácticas laborales, a los que sin embargo les restó fuerza obligatoria precisamente por no estar sus cláusulas contenidas en el reglamento interno de la empresa. Dictamen Ord. 3199/032, de 18 de julio de 2012.

${ }^{38}$ Materia regulada por el decreto supremo $\mathrm{N}^{\circ} 40$, de 1969. 
cargo de directivos en la debida aprehensión y asimilación del fenómeno y de todas sus características $^{39}$.

Diferente ha sido la situación de los denominados códigos de conducta, de ética o de buenas prácticas laborales, documentos que, como se adelantara, carecen de fuerza obligatoria, según lo ha dictaminado la Dirección del Trabajo ${ }^{40}$, pero que pueden llegar a marcar una pauta en el proceder de la empresa.

Si hemos partido del supuesto de que evitar la configuración del acoso es una forma de proteger eficazmente la vida y salud de los trabajadores, las actividades promocionales constituyen una verdadera obligación del empleador, cumpliendo así, a lo menos en parte, con el mandato legal contenido en el artículo 184 del Código del Trabajo.

Es indudable que nuestro legislador omitió toda referencia a las actividades preventivas, lo que no significa, como se ha venido diciendo, que estas no constituyan una obligación para el empleador. A diferencia de lo acontecido con la regulación del acoso sexual, no se incluyó una instancia previa de investigación que, según se manifestó en el estudio de la ley ${ }^{41}$, habría producido un considerable efecto disuasivo. La omisión de estas instancias no parece constituir, sin embargo, un obstáculo para su implementación, tan es así que han sido dictadas diversas resoluciones y protocolos para la vigilancia de riesgos psicosociales en el trabajo, normando la prevención de conductas factibles de configurar acoso laboral y ello, incluso desde antes de la dictación de la Ley $\mathrm{N}^{\circ}$ 20.607, aun cuando dirigidas especialmente a la prevención de estas prácticas en el sector público ${ }^{42}$.

Se puede concluir, asimismo, que ello conllevaría resultados del todo positivos tanto para la empresa como para el sistema mismo, pues permitiría que los propios trabajadores distingan con efectividad cuándo se está siendo verdaderamente víctima

${ }^{39}$ Del tenor de las normas del reglamento $\mathrm{N}^{\circ} 40$ queda en evidencia la importancia que le confiere a los denominados riesgos tradicionales, frente a los emergentes, lo que obedece a una realidad histórica, dada la época de dictación del mismo. En efecto, se indica a modo ejemplar que el referido reglamento debe contener regulaciones relativas al uso correcto y cuidado de los elementos de protección personal; el uso u operancia de todo elemento, aparato o dispositivo destinado a la protección contra riesgos; la conservación y buen trato de los elementos de trabajo entregados para uso del trabajador; la obligatoriedad de cada cual de dar cuenta de todo síntoma de enfermedad profesional que advierta o de todo accidente personal que sufra, por leve que sea; la cooperación en la investigación de accidentes; la comunicación de todo desperfecto en los medios de trabajo que afecten la seguridad personal; el acatamiento de todas las normas internas acerca de métodos de trabajo u operaciones o medidas de higiene y seguridad; la participación en prevención de riesgos de capataces, jefes de cuadrillas, supervisores, jefes de turno o sección y otras personas responsables.

${ }^{40}$ En Dictamen Ord. 3199/032, se concluyó que las cláusulas contenidas en el código de ética de determinada empresa, además de establecer obligaciones que atentaban en contra de los derechos fundamentales de los trabajadores, carecían de fuerza obligatoria, al no estar replicadas en el reglamento interno de higiene y seguridad.

${ }^{41}$ En Historia de la Ley $N^{\circ} 20.607$, p. 109.

Disponible en: file://Users/ruthgabrielalanatafuenzalida/Downloads/HL20607\%20(1).pdf) Visitado el $10 / 8 / 2015$.

42 Destacan, por ejemplo, el Procedimiento de Denuncia sobre Acoso Laboral de la Intendencia de la Región de La Araucanía de 2009 y las Orientaciones para la Prevención del Acoso Laboral en los Servicios Públicos, de la Dirección Nacional de Registro Civil, de 2010. 
de conductas de acoso antes de que los daños en la salud del trabajador se produzca, lo que no le quita el carácter de acoso laboral, según se dirá a continuación.

\section{Conductas de ACOSO Laboral Que nO PRODUCEN INCAPACIDAD EN EL TRABAJADOR}

El legislador en la conceptualización de la figura no exige como consecuencia del acoso laboral la presencia de alguna lesión ni, menos aún, de la declaración previa de un accidente del trabajo o de una enfermedad profesional sino solamente la existencia de menoscabo, maltrato o humillación, por un lado, o amenazas o perjuicio de su situación laboral o sus oportunidades en el empleo, por el otro. En otras palabras, no es posible exigir la calificación de una patología de carácter profesional en la víctima para ser merecedora de tutela frente al acoso laboral. No obstante ello, será de habitual ocurrencia que la salud del trabajador se vea afectada, especialmente su salud psíquica debido a los ataques o vejaciones de los que ha sido objeto ${ }^{43}$. Lo dicho no significa, eso sí, que la existencia de enfermedad sea requisito para la configuración misma del fenómeno, pero sin duda puede constituir una demostración objetiva de la calidad de acosadoras de conductas que consideradas aisladamente pueden resultar inocuas, pero no lo son al haberse reiterado en el tiempo. Así entonces, la existencia de afectaciones a la salud constituirá, normalmente, además de un claro indicio de la existencia de conductas de acoso, la materialización del daño indemnizable para la víctima.

Por otra parte, la ley se ha limitado a exigir la existencia de acoso, maltrato o humillación, pero sin efectuar una graduación en cuanto a la gravedad de las mismas, por lo que, configurándose estas consecuencias, se habrá configurado también el fenómeno y serán esas circunstancias las que deberán calificarse a la hora de cuantificar el daño tanto patrimonial como no patrimonial ocasionado a la víctima.

\section{CONClusiones}

En toda organización laboral es una realidad la factibilidad de la materialización de conductas constitutivas de acoso laboral, fenómeno que, por tanto, constituye un riesgo laboral. Las consecuencias o patologías que puede producir en el trabajador no se encuadran jurídicamente en el concepto de enfermedades profesionales, pues no son el resultado del ejercicio directo de una profesión u oficio determinado, según lo exige el artículo 7 de la Ley $\mathrm{N}^{\mathrm{0}}$ 16.744. Sin embargo, sí cumplen con las condiciones que el artículo 5 de la Ley $\mathrm{N}^{\circ} 16.744$ exige para ser consideradas como accidente del trabajo. Y ello, no obstante que la Superintendencia de Seguridad Social ha sostenido

${ }^{43}$ Blancas, C. El acoso moral en la relación de trabajo. Colección Derecho PUCP, Monografías, Palestra Editores S.A.C., Lima, Perú, 2007, p. 29. 
una posición amplia al determinar la relación existente entre las neurosis profesionales y la ocupación de la víctima, pues, como se analizó, el organismo administrativo hace aplicación de los parámetros que la ley exige para calificar determinada situación como accidente del trabajo, mas no como enfermedad profesional, esto es, que la incapacidad se haya producido por causa u ocasión del trabajo.

Si bien las consecuencias de uno u otra (accidente o enfermedad profesional) pueden ser en general las mismas, conceptualmente es necesario marcar una diferencia, pues aceptar que ellas son consecuencia directa del ejercicio de una profesión u oficio implica concluir que necesariamente debe convivirse con esas conductas, cuestión inaceptable, pues no se trata de acciones u omisiones esenciales de una actividad laboral, sino accidentales, de manera tal que es perfectamente esperable una prevención efectiva, en el sentido de propender a su absoluta eliminación del ambiente laboral, objetivo en el que juega un rol trascendental la actividad preventiva que debe diseñar, implementar y fiscalizar el empleador.

\section{BIBLIOGRAFÍA}

Agencia Europea para la Seguridad y Salud en el Trabajo Riesgos Nuevos y Emergentes para la Salud y Seguridad en el Trabajo. Observatorio Europeo de Riesgos, 2009. En http://www. cigsaudelaboral.org/files/descargas/RIESGOS\%20NUEVOS\%20Y\%20EMERGENTES.\%20 Observatorio\%20Europeo\%20de\%20Riesgos.pdf.

Blancas, C. El acoso moral en la relación de trabajo. Colección Derecho PUCP, Monografías, Palestra Editores S.A.C., Lima, Perú, 2007.

Babugia M.D. La prueba en el acoso laboral, Editorial BdeF, Enlace Industria Gráfica, S.L., Algete, Madrid, España, 2015.

Caplan, G. Principios de psiquiatría preventiva, Editorial Paidós, Buenos Aires, 1966.

Chappell, D. y Di Martino, V, The violence of work (ILO $3^{\mathrm{a}}$ Edición), 2006. En http://www. ilo.org/wcmsp5/groups/public/---dgreports/---dcomm/---publ/documents/publication/ wcms_publ_9221108406_en.pdf

FERnÁNDEZ J. "Perspectivas psicosociales en torno al acoso y violencia psicológica en el trabajo", en Correa, M. (coord.), Acoso Moral en el Trabajo. Concepto, prevención, tutela procesal y reparación de daños. Editorial Thomzon Aranzadi, 2006.

Hirigoyen M.F. Todo lo que hay que saber sobre el acoso moral en el trabajo. Editorial Paidós, Buenos Aires, 2014. Traducción de Montserrat Asensio Fernández.

Hirigoyen, M.F. El acoso moral. El maltrato psicológico en la vida cotidiana, Editorial Paidós, Buenos Aires, 2014.

Lanata Fuenzalida G. "El derecho de los trabajadores a la seguridad y salud en el trabajo como derecho fundamental”, en Caamaño, E. Y Pereira R. (coord.), Estudios de Derecho del Trabajo y de la Seguridad Social. Doctrina chilena y extranjera, Editorial AbeledoPerrot, Santiago, 2012.

Lanata Fuenzalida G. Manual de legislación previsional. Thomson Reuters, Santiago, 2014, segunda edición.

Martín, M. L. El Derecho de los Trabajadores a la Seguridad y Salud en el Trabajo CES Consejo Económico Social, 2006.

Ministerio de Salud, Protocolo de Vigilancia de Riesgos Psicosociales en el Trabajo. 2013. En http:// web.minsal.cl/portal/url/item/e039772356757886e040010165014a72.pdf 
Moreno B. "Factores y riesgos laborales psicosociales: conceptualización, historia y cambios actuales", en Medicina, seguridad y trabajo, vol.57, suppl.1, 2011.

NúÑez González, C. Prevención de riesgos laborales en Chile. Alcance y contenido del artículo 184 del Código del Trabajo. Librotecnia, Santiago, 2014, segunda edición actualizada.

Olarte, S. "La incidencia del acoso moral en el ámbito del sistema de Seguridad Social: hacia la equiparación de las enfermedades psicolaborales”, en Correa, M. Acoso Moral en el Trabajo. Concepto, prevención, tutela procesal y reparación de daños, Editorial Aranzadi S.A., Navarra, España, 2006.

Organización Internacional del Trabajo, "Factores Psicosociales en el Trabajo: Naturaleza, incidencia y prevención”, en: Serie seguridad, higiene y medicina del trabajo. Ginebra, 2015, núm. 56. En http://www.ilo.org/wcmsp5/groups/public/---americas/---ro-lima/documents/ publication/wcms_180285.pdf

ORGANIZACIÓN Internacional del Trabajo. Estrés en el trabajo: Un reto colectivo. Servicio de Administración del Trabajo, Inspección del Trabajo y Seguridad y Salud en el Trabajo, LABADMIN/OSH. Ginebra: OIT, 2016. En http://www.ilo.org/public/libdoc/ilo/2016/490658.pdf

Palomeque, C., Conferencia Inaugural del "Encuentro Iberoamericano Riesgo y Trabajo", Universidad de Salamanca, Fundación MPFRE, pronunciada el 11 de noviembre de 1991, en Actualidad Laboral, núm. 4, semana 27 enero-2 febrero, 1992.

Rodríguez G. y San Martín C., "La protección por la Seguridad Social de los riesgos psicosociales”, en González, F. Y Hierro, F. (coord.), Los Riesgos Psicosociales: Teoría y Práctica, Editorial Aranzadi S.A., Navarra, España, 2009. 